\title{
Ancient Modes of Philosophical Inquiry
}

\section{Introduction to the Special Issue}

\author{
Jens Kristian Larsen \\ Department of Philosophy and Religious Studies, Faculty of Humanities, NTNU, Trondheim, Norway \\ kristian.larsen@ntnu.no \\ Philipp Steinkrüger \\ Department of Philosophy II, Faculty of Philosophy and Educational Science, Ruhr University Bochum, Bochum, \\ Germany \\ philipp.steinkrueger@rub.de
}

\section{The Importance of Inquiry for Understanding (Ancient) Philosophy}

At least since Socrates, philosophy has been understood as the desire for acquiring a special kind of knowledge, namely wisdom, a kind of knowledge that human beings ordinarily do not possess. According to ancient thinkers this desire may result from a variety of causes: wonder or astonishment, the bothersome or even painful realization that one lacks wisdom, or encountering certain hard perplexities or aporiai. As a result of this basic understanding of philosophy, Greek thinkers tended to regard philosophy as an activity of inquiry (zêteesis) rather than as a specific discipline. Discussions concerning the right manner of engaging in philosophical inquiry - what methodoi or routes of inquiry were best suited to lead one to wisdom - became an integral part of ancient philosophy, as did the question how such manners or modes of inquiry are related to, and differ from, other types of inquiry, for instance medical or mathematical.

In this special issue of History of Philosophy \& Logical Analysis, we wish to concentrate in particular on ancient modes of inquiry. ${ }^{1}$ But, the reader may wonder, why do we talk about modes of inquiry, rather than methods? There are at least two reasons for this. First, the modern term 'method' gives connotations of something wider than inquiry: we talk of various methods for doing something, or for going about something, without thereby implying that we are directly engaged in inquiry into something. In another sense, however, method is narrower than inquiry; for a method proper prescribes in a strongly regulative way how to proceed in order to get from an initial state to another state. Whether there are any such prescriptions for philosophical inquiry is an open question, both now and in antiquity. Most ancient philosophers would agree, however, that there are, as it were, small-scale methods or techniques in philosophy, for instance the method or technique of disproving a claim by counterexample; and they would further agree that such methods play some role in inquiry. However, most real philosophical inquiries are far too complex to be carried out by relying on only one such method or technique. A proper method of philosophical inquiry would thus at least require a description of how these specific individual techniques can be combined. But even if no such largescale method can be discovered in philosophy, philosophical inquiry may still be possible and facilitated by certain modes or elements in a general account of such inquiry. This latter possibility is especially important for the sceptical school of the Pyrrhonists, who were keen on claiming that they were engaged in inquiry without subscribing to any of the various methodoi which had been developed up to this point, and, in fact, to any specific method of inquiry at all. It 
is also important because, for all the various modes or routes of inquiry discovered in antiquity, philosophy remained, at any rate wide and for many of the then philosophers, and to use a somewhat worn expression, a way of life or, more precisely, a type of life lived in pursuit of happiness. The modes of inquiry remained subservient to this; some stoics even suggested that the tools necessary for inquiry, in particular logic, could become a hindrance for philosophy if pursued merely for its own sake.

Inquiry is, we contend, not only one of the many interesting aspects that one needs to investigate in order to get a complete picture of a philosopher or a philosophical era (such as, for instance, the various views on nature, the mind, or the best life); rather, we believe that understanding inquiry is crucial for our understanding of philosophy, and in particular of ancient philosophy. One of the reasons for this is that the modes of inquiry a given philosopher chooses will - for better or worse - enable or disable him or her to discover certain truths (an empiricist will never be able to discover Aristotle's first principles), and it will shape the results he or she may eventually come to. In this sense we could say that the study of inquiry is even more fundamental than metaphysics - that is, if we hadn't absorbed Aristotle's lesson on the inseparability of the various aspects of metaphysics and indeed his account (in book III of the Metaphysics) that metaphysics, or simply philosophy or first philosophy, is inquiry-based.

As important as inquiry may be to understand the philosophy of a particular thinker, of an era, or even of philosophy in general, inquiry itself sometimes appears to lack properties that we think of as important for philosophy. It is commonly contended, for instance, that philosophy requires consistency; yet, inquiry may well proceed via inconsistencies. Moreover, some modes of inquiry may be entirely different from what is now, and in general, accepted as forming a part of philosophy. A possible example that comes to mind is Plato's use of myths, assuming, for the moment, that Plato uses myths to enable further progress in an inquiry concerned with a given philosophical matter. ${ }^{2}$ These somewhat surprising connections between the modes of inquiry and their results are one of the reasons why inquiry is such a fascinating research topic.

We contend that understanding the various modes of inquiry a given thinker may employ is crucial for understanding the philosophy of that thinker, and we think this is true for all eras and branches of philosophy. But perhaps ancient philosophy occupies a special place here, at least within western philosophy. While later traditions (for instance, the scholastic philosophy of the middle ages) relied to a great extent on the modes of inquiry that had been established in previous centuries, ancient philosophy, and in particular the early phase of ancient philosophy (at least up to and including Aristotle), had to lay the foundations. It is true, of course, that later philosophers (we are thinking of obvious examples such as Descartes and Husserl) also were keenly interested in the question of how philosophical inquiry ought to proceed. But the situation is markedly different, since these later thinkers developed their views on inquiry in opposition to established traditions, while the ancient philosophers were creating something entirely new - especially when it comes to the modes of inquiry - and they were aware of themselves as innovators and groundbreakers.

There are, therefore, at least two purposes for which studying philosophical inquiry in antiquity promises to be fruitful: (1) to understand philosophy in its incipient moment; (2) to understand a crucial condition (the chosen mode of inquiry) under which the respective ancient philosophers posed the questions and defended the answers they did pose and defend. Such observations have direct relevance for students of ancient philosophy. We believe, however, that studying the ancient philosophers' approaches to the questions and problems of inquiry can also (3) be beneficial for philosophers concentrating on other periods of philosophy, as well as for systematic philosophers. For the unique

2 For Plato, of course, the use of myths are not the only (or even the most important) mode of inquiry. For a general account of Platonic inquiry, focussing especially on the so-called early dialogues, see Politis (2015). 
situation the ancient philosophers found themselves in demanded unique reactions that are worth being considered by anyone interested in philosophical inquiry.

\section{$2 \quad$ A Tentative Map of Inquiry}

We think it is worth providing a map of the various issues pertaining to our topic, even though it will be, in all likelihood, incomplete. On the one hand, such a map will provide a framework for the individual contributions to this volume, some of which are highly specialized studies. On the other hand we hope that the map will provide a stimulus for further research, especially by highlighting the rather large areas that have not been touched on by the publications collected in this volume.

An entry-point into such a map that suggests itself is the question 'What makes philosophical inquiry special and how it is different, if it is different, from other forms of inquiry?'. At a general level, this is a question that is central to contemporary philosophy as well: in contrast to almost all other disciplines, the question of how one should define philosophy in order to set it apart from other intellectual activities is integral to philosophy itself. When it comes to the more specific question of what sets philosophical inquiry apart from other types of inquiry, we are thinking of four principal forms of inquiry that would need to be distinguished from one another: pre-philosophical inquiry, philosophical inquiry, scientific inquiry, and everyday inquiry. One does not have to follow Wilhelm Nestle's infamous Vom Mythos zum Logos in order to agree that the thinking - and with it, the mode of inquiry - of the first authors we tend to call "philosophers" is in a significant way different from those that came before. For instance, while there is a connection between the genealogical accounts of the world found in Hesiod's Theogony and the attempt of the early Greek philosophers to decide what the "principle" or beginning of everything is (water, for instance, or the Unlimited), it can hardly be denied that the way these two types of inquiry proceed differ significantly from each other. ${ }^{3}$

The second form of inquiry we want to demarcate from philosophical inquiry is the inquiry that we engage in on an everyday basis. In his Confessions (X, 18, 27), Augustine illustrates his own search for God with the parable from Luke 15:8 about the woman who lost a drachma and lit a lamp in order to search for it. She would not have been able to find it, Augustine points out, unless she had remembered it. This, one may argue, illustrates a general point about the conditions of everyday inquiry well known from Plato's Meno: if you do not know what you are looking for, you will not be able to find it (see Meno 8od5-e5). But in contrast to the everyday activity of searching for, and inquiring into, something, philosophical inquiry stands out, it may be argued, by the fact that philosophers in general reflect on the conditions of inquiry enabling them to inquire in the first place. So, while everyday inquiry should share many properties with philosophical inquiry (perhaps even more than the latter shares with pre-philosophical inquiry), getting clear on the distinctions between the two promises to be fruitful for our understanding of philosophical inquiry.

The third and last form of inquiry that we wish to distinguish from philosophical inquiry, which is scientific inquiry, requires a little more description. The term 'scientific' and its cognate 'science' are notoriously problematic when it comes to ancient philosophy. They are often used to translate epistèmē, the term used for the highest kind of knowledge by Aristotle. In this sense, of course, scientific inquiry and philosophical inquiry shouldn't be distinct, if indeed philosophy is to help us achieve wisdom, and wisdom is epistēme . A related problem is the demarcation of disciplines: sciences like biology, chemistry, or mechanics are nowadays strictly distinguished from philosophy, but in antiquity the distinction, at least in name, is not always so clear. Nevertheless, the modes of inquiry of philosophy and those of other disciplines are, in large part at any rate, distinct and this fact did not escape the ancient philosophers -

3 Note that by using the term 'pre-philosophical' we do not mean to say that whatever kind of thinking and inquiring is referred to with that designation has ceased to exist with the advent of philosophy. 
such a distinction is perhaps discussed most clearly, and probably also most famously, by Plato in the Republic, when he sets apart philosophical and mathematical inquiry (see especially $510 \mathrm{~b} 4-511 \mathrm{~d} 5$ ). We therefore stand to gain insights into the nature of the philosophical modes of inquiry, if we investigate them in relation to the inquiry taking place in other disciplines (like mathematics, biology, astronomy, medicine, etc., but also e.g. music or history).

Even more important might be the ancient philosophers' discussions of other disciplines and their observations regarding any differences between these disciplines and philosophy. We have already mentioned Plato and his verdict on the difference between mathematical and philosophical inquiry in the Republic, but other authors come to mind, too. At the beginning of the Nicomachean Ethics, Aristotle observes that one would speak adequately if one obtains the clarity that is appropriate for the subject matter investigated; for one should not seek precision in the same way in all types of discourse. In other words, if the inquiry is concerned with a subject matter that does not allow for mathematical precision, one should not demand that the inquiry arrives at such precision (see Nicomachean Ethics I.3). Conversely, the position of the scientists vis-à-vis philosophy is likewise important. In the opening chapters of the Hippocratic treatise On Ancient Medicine, for example, the writer contrasts his own investigation of disease and its causes with that of other writers who engage in metaphysical speculation as part of their inquiries. ${ }^{4}$

A related question is the relationship of inquiry, and the account of inquiry, and epistemology. Classically, epistemology is primarily concerned with the question of what knowledge is (and related concepts, like, for instance, justification), and often questions about how we may acquire knowledge (for instance, by discovering the dependence of a property on an essence) play into answering the primary question and thus are part of epistemology. The explicitly formulated epistemologies of the ancient period, like Aristotle's Posterior Analytics, which has a lot to say about knowledge and its acquisition, may be thought of as including the treatment of inquiry. However, it appears, to stick with the example of Aristotle, that for him philosophical inquiry is different from the theory described in the Posterior Analytics. ${ }^{5}$ This is true both for the inquiries that Aristotle himself undertook and which we can find in his extant works, but also for his explicit statements on how one should go about philosophical inquiry (for instance, in Metaphysics III.1).

While we think that, pending any conclusive arguments to the contrary, the study of philosophical inquiry is not absorbed by general epistemology, it is obvious that there are very strong relationships between the two fields that need to be explored. These concern questions such as: Is the concept of knowledge dependent or independent of the concept of inquiry and vice versa? What is the epistemological status of those iHowevertems in an inquiry that, all going well, lead up to the desired goal, knowledge? The above-mentioned peculiarity, namely, that inquiry does not necessarily need to proceed via known truths, or not via truths at all, and may yet lead, or contribute to leading, nonaccidentally, to truth and knowledge, belongs here. And it may not even be necessary, as we said, that the inquiry observes consistency-requirements.

Another aspect of inquiry worth considering in connection with the question how inquiry and epistemology connect is what mental traits are conducive to achieving knowledge and wisdom. In the Republic (see 503c1-d8 and 535a9-c9) and the Theaetetus (144a1-b6), Plato lists a number of virtues as being of crucial importance for philosophical inquiry and, more generally, for acquiring knowledge, including: good memory, gentleness, and courage. In addition to concerns more in step with classical epistemology, e.g. regarding the nature of knowledge, Plato thought

4 Throughout its history, philosophers have shown a continuous interest in the practice of their intellectual neighbours, which has certainly reached its peak so far in the $20^{\text {th }}$ and $21^{\text {st }}$ centuries, a period that has not only seen the most intensive philosophical reflections on the sciences and their methods like mathematical physics, but also a previously unknown desire on the part of the philosophers to emulate the practices of the sciences.

5 By this statement we neither want to suggest a developmentalist reading of Aristotle's work nor claim that the concepts developed in the Posterior Analytics are inapplicable to philosophy. Rather, we think that the Posterior Analytics is not primarily about inquiry, no less philosophical inquiry. 
essential the question which virtues or excellent character traits are required for the type of inquiry that will, ideally, lead to knowledge and wisdom. Aristotle held similar views, one may argue, in the Nicomachean Ethics (see NE 1095a411), as he claims that only those who have already acquired a suitable moral upbringing will be able to benefit from the inquiry into the best possible life.

These questions, how epistemology and inquiry are related, and what virtues are required, if any, for conducting a successful inquiry, are still - or again - part of the contemporary discussion, even if they have, arguable, been less central to the debates of the $2 \mathrm{O}^{\text {th }}$ and the $2 \mathrm{1}^{\text {st }}$ century than some believe they should have been. ${ }^{6}$

There are a number of further fields of inquiry-related topics that are of crucial importance to ancient modes of philosophical inquiry. Since we are unsure whether they can be grouped into larger regions we will simply go through them in turn and order, noting, wherever possible, common borders with other regions.

A central concern of Plato's was, as mentioned, to demarcate philosophical inquiry from mathematical inquiry. For Plato, this demarcation depends on his conception of dialektike, the "science of discourse" (Soph. 253d1-3) that constitutes what we may, with Charles Kahn, call the "technical heartland" of Platonic philosophy (1996, 292). At its most basic level, Platonic dialectic may be described as a specific way of inquiring into something via questions and answers, a procedure that according to Plato mirrors the nature of discursive thought (dianoia): to think discursively consists in posing questions to oneself about something one inquires into or investigates and in seeking answers to these questions (Theaetetus 189e6-19oa7, see also Sophist 263e3-5 and compare with Gorgias 449b4-8 and Protagoras $334 \mathrm{c} 8-336 \mathrm{~d} 5$ ). Such inquiries, it is commonly claimed, should ideally terminate in definitions; definitions not only of our words and concepts, but also, and primarily, of the phenomena designated by our words and concepts. Two key procedures for successful inquiry Plato recommends is to distinguish things that look alike but are not and to recognize likeness in things that may not look alike (see Phaedrus $265 \mathrm{~d} 3-266 \mathrm{~b} 1$ and Sophist $253 \mathrm{~d} 1-3),{ }^{7}$ procedures commonly referred to as the method of collection and division. What precisely collection and divisionHowever entails and how one is to proceed when one is engaged in it, is still a question of much debate.

Rightly or wrongly (we think wrongly), inquiry through questions and answers and the procedures of collection and division are sometimes seen as two versions of what is now called conceptual analysis. However that may be, conceptual analysis is certainly an important topic for anyone interested in philosophical inquiry, as are the other forms of analysis, such as mathematical or regressive analysis, which have been claimed to have been a great methodological inspiration for Plato, ${ }^{8}$ and possibly also for Aristotle. ${ }^{9}$

A further procedure central to Plato's conception of dialectic, and one that has been argued to have a direct connection to mathematical analysis (see Menn 2002), is the dialectician's ability to use hypothetical reasoning, commonly referred to as the hypothetical method (see e.g. Phaedo 99d4-10oe3). It is controversial how this method is to be understood and whether or not Plato changed his conception of it over time. At its most simple level, however, the uses of hypotheses in Plato consists in inquiring into something by investigating what follows from assuming that something and also what follows from not assuming it (see Parm.136a4-c5). At this level of generality, it is perhaps fair to say that the method foreshadows the later hypothetico-deductive method.

One of the more curious modes of inquiry can be seen in Aristotle's so-called endoxic method. According to the endoxic method, one of the early steps of an inquiry is the collection of endoxa (reputable opinions). What precisely is

$6 \quad$ See Turri et al. (2017).

7 It is a controversial matter how the various procedures that are mastered by the dialectician - in particular collection and division, hypothetical reasoning, and refutations arrived at through questions and answers - fit together. We neither presuppose that they all fit together in one science nor that Plato developed and changed his understanding of them over time, but merely indicate that they are all described as belonging to this science in various Platonic dialogues.

8 For analysis and philosophy in general, see Beaney (2014a); for analysis in ancient philosophy see Beaney (2014b).

9 Nicomachean Ethics 112b15-24; see Hintikka \& Remes (1974, 1). 
supposed to happen with these endoxa is not entirely clear, despite a seemingly straightforward prescription (Nicomachean Ethics 1145b2-7), according to which the truth of these endoxa or at least a subset of them (either the majority or the most authoritative of them) have to be proven. It seems important that Aristotle, in the Topics (10oa2530 ), identifies a type of deduction that proceeds from endoxa and calls it dialectical. It is controversial how we are to understand Aristotle's conception of dialectic, but, since many of Aristotle's own philosophical inquiries seem to take as their point of departure endoxa (see e.g. Wieland 1962, Irwin 1989), endoxa appear to play an important role in philosophical inquiry according to Aristotle.

A special case of the endoxic method, or some variant of it, is the use of the history of philosophy. The most famous example of such an approach to inquiry is without doubt Aristotle's review and criticism of his predecessors in the Metaphysics and in the Physics, but recourse to philosophers of the past can also be noted before and after Aristotle. In the case of Plato, it is perhaps even easier to see how he employs other philosophers (e.g. Heraclitus and Parmenides) in his own investigation (see Theaetetus 179c1-184b1 and Sophist 242c4-245e8): accurate doxography is much less important than the possibility to advance the inquiry. In later antiquity we meet a special variant of the use of the history of philosophy as a mode of inquiry, namely the exegesis and commentary, which characterizes both the Peripatetic (e.g. Alexander of Aphrodisias) as well as the Neoplatonic (e.g. Proclus) schools of this period. The history of philosophy and its employment in ancient authors connects, at least in the case of Aristotle, with another question, also debated in contemporary philosophy (see e.g. Chalmers 2015), namely whether or not there is progress in philosophy. This question concerns the very nature of philosophical inquiry, for it asks whether philosophical inquiry is fundamentally different from other forms of inquiry, and especially empirical inquiry, which quite clearly shows progress.

A related mode of inquiry is the use of intuitions, i.e., to contrast with the endoxic method, not the reputable opinions of authorities on the subject, but our own or those of the agora-goer. Intuitons of course play a big role in contemporary experimental philosophy. For the ancient period, one could point to examples in Plato. One example would be Anytus' claim that sophists are "the ruin and corruption of those who associate with them" (Meno 91c4-5; trans. Long-Sedley), a claim advanced despite the fact that Anytus has not had any personal dealings with sophists (92b7-c5). Another would be Socrates' use of common intuitions about what is right or wrong in dialectical encounters, for instance when he asks Polus whether he accepts that committing injustice is, if not bad, at least shameful (Gorgias 474c5-9). This is a common move Socrates makes, in order to use those intuitions accepted by his interlocutors for the purpose of defeating the position they are defending. One could also point to Aristotle's Metaphysics (982a6-10), in which one of the early steps of his inquiry into the nature of wisdom is represented by a recording of the "assumptions" (hupolēpseis) one has about the character traits of the wise man. Intuitions also served an important role in the examples used by the hellenistic schools to corroborate their own positions or refute those of their contenders. ${ }^{10}$

One of the most fascinating modes of inquiry and central to philosophy as conceived of by at least Plato and Aristotle is the use of aporiai (puzzles or difficulties)." The idea that thinking carefully about puzzles or hard difficulties may promote philosophical inquiry is, of course, central to modern philosophy as well - one need only mention Russell's “On Denoting” or Husserl's Prolegomena. To illustrate how this mode of inquiry works in ancient philosophy, we may note that Plato's dialogues commonly depict inquiries into various opinions entertained by Socrates' interlocutors and that such inquiries typically lead, at one point or another, to a serious problem, an aporia, because it becomes clear that the opinion investigated entails something that conflicts with certain other opinions we

10 See Ierodiakonou (2018), 39-40.

11 For the Platonic and Aristotelian use of aporiai in inquiry, see in particular Politis (2003, 2004, 2006, 2015) and Karamanolis \& Politis 2018. 
have reasons for accepting. To illustrate the point with the Protagoras: At the beginning of an inquiry, we may have good reasons for believing that virtue is something that can be taught; in the process of the inquiry, however, good reasons for believing that it cannot be taught come to light and we therefore end up in aporia, being in an impasse (for a more detailed analysis, see Politis 2008 and Politis 2012). But situations where we appear to have good reasons for accepting mutually exclusive opinions are not an impediment to philosophical inquiry. On the contrary, both Aristotle and Plato recognize that such situations set in motion the deepest philosophical inquiries (compare Theaetetus 154b1155d7 with Metaphysics III.1, 994a24-995b4). Certain aporiai, then, are very valuable for philosophical inquiry, at least according to Plato and Aristotle, and perhaps they are even necessary for some kinds of philosophical inquiry as Aristotle remarks in the Metaphysics (III.1, 995a24).

A different aspect of dialectical inquiry worth considering is the use of examples. Examples, it might seem, are apt to impede philosophical inquiry. For an example is by its nature something particular and often drawn from the realm of perceptibles, while philosophical inquiry, at least as some philosophers conceive of it, is concerned with what is universal and hence non-perceptible. On the other hand, we are unable to experience the world except through our senses and it is, one may argue, impossible for us to conceive of anything in complete isolation from what is particular and sense-perceptible. This curious difficulty was not unknown to ancient philosophers. A particularly interesting case is Plato. In the Phaedo, Plato's Socrates insists that knowledge is concerned with what is non-percepticle and even that the inquiry directed at what is non-perceptible should, to the extent possible, avoid relying on sense-perception at all (see $\left.65 \mathrm{e}_{7}-66 \mathrm{a} 7\right)^{12}$ In the Statesman, on the other hand, it is remarked that it is difficult to point out any of the biggest matters (for instance what statesmanship is) without using examples (277 $\mathrm{d} \mathbf{1}-4)$. It is further suggested that someone who understands one of these matters may use sense-perceptible examples to help someone who does not yet understand it by pointing to the structural similarity between a sense-perceptible example and what it is meant to exemplify; in this way, examples may help human beings in becoming more dialectical (see $285 \mathrm{~d} 5^{-} 7$ and $287 \mathrm{a} 3$ ). This way of proceeding, one may argue, is characteristic of Plato's Socrates - for he commonly brings in examples in the dialogues that are simple and easy to understand for the purpose of illustrating essential features of something that is not easy to understand.

A special kind of example can be seen in the thought-experiment. ${ }^{13}$ While this mode of inquiry is not nearly as often used in antiquity as it is in contemporary philosophy, which has seen the emergence of entire genres of thoughtexperiments (like the trolley-problems), ancient philosophers nevertheless employed this mode from time to time: thought-experiments like the ship of Theseus, Plato's ring of Gyges, and Zeno's paradoxes regularly attract the attention of modern critics. ${ }^{14}$ Others, like Plotinus' eye of the universe (Enneads IV.5,3 and 8), which supposes that the universe has an eye and asks what, if anything, it would see if it looked outside of itself, are less well-known. Whether these diverse philosophers took to the mode of thought-experiment for the same or different purposes, and how their respective inquiries proceed, are questions the answers to which promise to be illuminating for the student of inquiry.

It has, finally, been suggested that there is a special case of thought-experiment in antiquity, namely myths. ${ }^{15}$ Whether or not this suggestion is correct, it is undeniable that some ancient philosophers avail themselves of mythical story-telling in their works and do so, one may argue, for the purpose of inquiring into controversial subject-matters.

See Politis (forthcoming) and his contribution to this volume.

What precisely thought experiments are, how many different kinds of them can be distinguished, and which roles thought-experiments can or cannot play, is a hotly debated topic in contemporary philosophy. See e.g. Stuart et al. (2018).

For thought-experiments in ancient philosophy in general, with particular emphasis on the Hellenistic Schools, see Ierodiakonou (2005, 2011, and 2018); for Plato, see Becker (2018), and for Aristotle, see Corcilius (2018). It is possible to see a connection between the hypothetical mode of reasoning discussed above and the use of thought-experiments; for more on this, see Ierodiakonou (2018, 33-34).

5 For a discussion of myth and thought-experiments in Plato, see Becker (2018, especially $45^{-46}$ and $48-50$ ); for Plato's myths more generally, see for instance Brisson (1998); Janka \& Schäfer (2002); Partenie (2009); Collobert et al. (2012). 
This mode of inquiry, if it is indeed such a mode, is most readily associated with Plato's dialogues, where both Socrates and Plato's other main characters appear to use myths for the purpose of elucidating a particular difficult matter. Two examples may suffice. In the Timaeus, the main character of the dialogue after which it is named, engages in a grand myth or, more precisely, a "likely story" (see $29 \mathrm{~d} 2$ ) about the creation and structure of the universe, a story that one might regard as thought-experiment: what would the world look like if it was in fact ordered by divine reason the way Anaxagoras had suggested. In the Statesman the question what true statesmanship is is investigated through the myth of the reversed cosmos (268e4-274e3) that again may be regarded as a thought-experiment: if we assume that the world is not guided by divine providence, as it may have been in a long forgotten past, but is rather a place wherein human beings must toil and invent various types of crafts in order to survive at all, what will true statesmanship look like? Other myths set out in Plato's dialogues fit the thought-experiment hypothesis less well, however. The myths about the afterlife, for instance, found in the Gorgias, the Phaedo, and the Republic, seem to reveal something about the nature of human beings in a "non-scientific" manner of discourse, as does the myth about the original state of human beings in Aristophanes' speech in the Symposium.

Concluding this overview of various inquiry-related topics, we return to those specific small-scale methods we mentioned in the beginning. These may not only be employed with a view to achieving a specific task or step in a greater endeavor, such as falsifying an all-quantified claim by counterexample, but may also be counted as elements in a group of devices which might help a philosopher to discover possible ways forward in an inquiry. This group of heuristics will likely prove to be very heterogeneous, possibly comprising such diverse elements as graphical representations (e.g. Socrates' use of geometrical drawings in Plato's Meno), general techniques of thinking and arguing (e.g. Aristotle's Topics), or even mechanics. ${ }^{16}$

Inquiry is, then, a very rich subject with influences from and implications for many different areas of philosophy, most notably epistemology and metaphysics. Detailed investigations of the various topics thus promise to advance our understanding not only of ancient philosophy but of philosophy more generally. Our tentative map shows that many inquiry-related topics are central not only to the thought of ancient but also of contemporary philosophy; we therefore believe that the historian of philosophy and the contemporary philosopher stand to profit considerably from each other's work. This volume offers 10 original contributions to our topic which focus on Heraclitus, Plato, Aristotle, the Stoics, and the Skeptics. In the next section, we will summarize these contributions and point out some of the connections these articles have to the different topics identified in the map.

\section{Investigations of Modes of Inquiry in this Volume}

Keith Begley turns to the historically earliest author in our issue, Heraclitus. One important element in Heraclitus' thought concerns, as Begley argues, his views of philosophical inquiry. Heraclitus warns the would-be philosopher not to be content with polymathy, the acquaintance with many things, as polymathy only provides a naive form of pseudowisdom. Proper philosophical inquiry, on the other hand, has to seek the unity of the things it investigates. This feature, Begley argues, sets Heraclitus apart from the naïve paratactic metaphysics of his polymathic ancestors and contemporaries. Indeed, it is through this feature that we may take Heraclitus to be a philosopher and this, according to Heraclitus is what sets philosophical inquiry apart from, on the one hand, ordinary inquiry, and, again according to Heraclitus' view, misguided attempts at understanding nature on the other hand.

As we said, in the past years, research in ancient philosophy has seen a steady rise in publications on the notion and role of inquiry. Plato has proved to be a particularly interesting author when it comes to this subject, and a growing 
number of scholars by now agree that understanding Platonic inquiry is crucial to our understanding of Plato's philosophy. Vasilis Politis' contribution to this issue raises this insight to a new level when he investigates the relation of Plato's account of knowledge and his account of inquiry as this relation is presented in the Phaedo. Politis argues that the former is dependent on the latter and that therefore we can only understand Plato's concept of knowledge when we understand his concept of inquiry. If Politis is right, it demonstrates that we should be careful about attributing to Plato an epistemology or an account of knowledge that can be understood in isolation from his account of inquiry. ${ }^{17}$

Given that one of the self-characterizations of the ancient skeptic school was, according to Sextus Empiricus, to be zètétike (disposed to inquire), engaging with the Skeptics promises to be particularly fruitful for the student of the ancient modes of inquiry. However, inquiring also presented the Skeptics with a problem, as any commitment to a method would threaten to damage their skeptical stance, and, in consequence, would deny the Skeptics the tranquillity they desire. This is the problem James Hankinson investigates. Hankinson concludes that Sextus Empiricus and his branch of Skepticism can indeed inquire without having a method, or, at any rate, without having a method which would be problematic in the sense just mentioned.

Pyrrhonian inquiry, critics argue, aims at tranquility instead of truth; therefore, it is not real inquiry and its aim is unattractive to anyone but the skeptic. Máté Veres argues that Pyrrhonian inquiry, while aiming at tranquility, originates in the perplexity that arises when philosophically inclined people encounter conflicting appearances and that tranquility results from the inquiry brought about by such encounters. He further argues that passages in Plato and Aristotle demonstrate that they, too, see philosophical inquiry as originating in such encounters, namely the encounters with puzzles or difficulties discussed above. The skeptic's claim that they inquire also on behalf of their dogmatic colleagues is thus less partisan than it might appear: they, like Plato and Aristotle, one may argue, see the state of perplexity as the origin of philosophy, even if they understand the goal of philosophical inquiry in a radically different manner. ${ }^{18}$

A puzzle well-known to philosophers of all ages is presented by Scott Aikin. We begin to philosophize because we seek to understand how we could become better persons. Soon, however, we realize that in order to investigate that question we first need to get clear on certain other issues. Put differently, we need to master the various modes of inquiry, in particular logic, in order to ensure that our inquiry proceeds the way it should. Years later, however, we find ourselves buried in scholastic distinctions of technical terms and no closer to answering the question that originally prompted our inquiry: the means have become ends. Epictetus, Aikin argues, was acutely aware of this problem and recommends that philosophers perform a double-vision that is directed at both methodological and valuational requirements in order to stay on track.

Evan Rodriguez addresses a particular aspect in Plato's method of inquiry. Plato's methodological debt to sophists like Gorgias, Rodriguez argues, is greater than common assumptions about this relation would allow. This concerns in particular the sophistic method of "playing (or arguing) both sides", which can be attributed to Gorgias. This method, Rodriguez argues, has its Platonic counterpart in what could be called "exploring both sides", an investigative strategy regularly employed by the Platonic Socrates. Rodriguez thereby casts light on a central feature of Platonic method, the use of hypotheses; for exploring both sides is, as the Parmenides demonstrates, a mode of hypothetical reasoning, even if it is not identical with the use of hypotheses discussed in the Phaedo, the dialogue most critics rely on when

17 In the contemporary discussion, this possible co-dependence of knowledge and inquiry has recently been considered by Friedmann (2015).

18 The necessity to suspend judgment for a real inquiry to take place has been emphasized not only by the Skeptics and philosophers like Plato and Aristotle, as Veres shows. It is also a feature of later philosophers like Descartes, and has recently been picked up again by Friedman (2015 and 2017). 
discussing hypothesis in Plato. Indeed, the Parmenides suggests that exploring both sides is a specific kind of hypothetical reasoning that is on a par with other modes of hypothetical reasoning in Plato.

Guy Schuh argues that Aristotle employs an exploratory investigative strategy in the inquiry contained in the Nicomachean Ethics. Aristotle frequently posits positions that are rejected at a later stage in that inquiry - the reputable opinions discussed above - and Schuh argues that they are introduced also for pedagogical reasons. This strategy allows Aristotle to tentatively adopt a position that seems attractive but may be incorrect, thereby illustrating how philosophical inquiry may proceed. Schuh exemplifies this strategy by focusing on three positions central to the overall argument of the $N E$, positions that Schuh emphasizes are rejected in the course of that argument: that courageous people do not fear death, that friendship consists in mutually recognized goodwill, and that virtuous people engage in virtuous actions for the sake of the actions themselves.

Isocrates famously argued that contemplation or theoria is too demanding for human beings to be worth the effort, or not to be attainable at all. Analyzing Aristotle's response to that argument in the Protrepticus, Matthew Walker raises the question whether or not there is progress in philosophy. In the Protrepticus Aristotle argues that philosophy is, overall, easy. This argument, Walker urges, is a neglected source for understanding Aristotle's ethical views that offers fresh light on Aristotle's defense of the contemplative life that he endorses at the beginning of his Metaphysics and identifies as a requirement for human happiness in the Nicomachean Ethics. The argument may also prove to be of benefit to the contemporary discussion: is there progress in philosophy and how is it supposed to be possible ${ }^{19}$

Justin Vlasits approaches Pyrrhonian inquiry through Sextus Empiricus' Outlines of Pyrrhonism II and argues that Sextus here presents a unified and ambitious inquiry with the unstated goal of arguing for the conclusion that we should suspend judgement on the effectiveness of dogmatic methodologies. In other words, Sextus argues that inquiry does not stand in need of a method. The claim that Pyrrhonian inquiry, in contrast to dogmatic inquiry, is only sham inquiry, presupposes that dogmatist inquiry is set apart from skeptical inquiry through a reliable method that leads to stable truths. Sextus seeks to counter this claim by showing that methodologies employed by dogmatists are deeply puzzling, that they need to be inquired into, and that the distinction between inquiring through a method and not doing so is far from clear.

Benjamin Wilck addresses a problem facing the Pyrrhonian skeptic when it comes to suspending judgement about scientific definitions. The skeptic's ability to suspend judgement depends on her ability to advance pairs of equally convincing arguments or considerations for and against a given proposition. But in Adversus Mathematicos III Sextus only advances arguments against geometrical definitions, as critics have remarked, and his method looks like negative dogmatism, not scepticism. Wilck argues that this problem cannot be addressed just by supplying Sextus' text with arguments in favour of the definitions he attacks; for ancient geometers did not advance arguments in favour of their definitions. He then proceeds to evaluate various strategies one may use to supply such arguments.

As we have seen, some contributions touch on some very general questions pertaining to philosophical inquiry, such as the questions what characterizes philosophical inquiry (Begley), what relation obtains between knowledge and inquiry (Politis) and whether or not a specific method is needed in order to engage in inquiry (Hankinson). Further general questions are whether what the Pyrrhonist school is engaged in can be regarded as inquiry (Veres), and whether or not the modes of inquiry we utilize may end up standing in the very way of the goal of inquiry, i.e. wisdom (Aikin). More specialized questions concern Plato's use of hypothetical reasoning and its connection to the sophist Gorgias (Rodriguez), the way the use of reputable opinions structure the inquiry in Aristotle's Nicomachean Ethics (Schuh), and 
whether or not there is progress in philosophy (Walker). Finally we find specific questions pertaining to the mode of inquiry the Pyrrhonist school engaged in, namely regarding the possibility and necessity of suspending judgement on the effectiveness of dogmatic methodologies (i.e. more or less what the intended dogmatists understood under the heading of 'logic') (Vlasits), and whether or not it is possible to suspend judgement on mathematical principles through the creation of equipollence (Wilck). We hope that these contributions will intensify interest in the topic of inquiry in the scholarly community and help stimulate future research into inquiry. As our introduction has hopefully made clear, this volume engaged with just a fraction of the subject-matter. The explorer who wishes to investigate the question how different modes of inquiry have structured and continue to structure our very conception of philosophy faces a largely uncharted territory that is bound to offer new vantage points from which we may look at the regions of philosophy we think we already know with fresh eyes.

\section{Acknowledgements}

The editors would like to thank Laura Candiotto for help in tracking down contemporary literature on inquiry and epistemology, as well as the participants of the workshop 'Ancient Modes of Philosophical Inquiry' (Bochum, 13-14 September 2018). Special thanks are due to Vasilis Politis for his great help in this project. We would finally like to thank the numerous reviewers for their invaluable work. All remaining errors in the introduction remain our own. 


\section{Bibliography}

Beaney, M. 2014a. Analysis. In: Zalta, E.N. (ed.), The Stanford Encyclopedia of Philosophy (Summer Edition 2018), URL: $<$ https://plato.stanford.edu/archives/sum2018/entries/analysis/>. Accessed: June 4, 2020.

Beaney, M. 2014b. Ancient Conceptions of Analysis. In: Zalta, E.N. (ed.), The Stanford Encyclopedia of Philosophy (Summer Edition 2018), URL: <https://plato.stanford.edu/entries/analysis/s2.html>. Accessed: June 4, 2020.

Becker, A. 2018. Thought Experiments in Plato. In: Stuart, M. T., Fehige, Y. \& Brown, R. J. (eds.), The Routledge Companion to Thought Experiments. London - New York: Routledge, $44-56$

Berryman, S. 2009. The Mechanical Hypothesis in Ancient Greek Natural Philosophy. Cambridge: Cambridge University Press.

Brisson, L. 1998. Plato the Myth Maker. Nadaff, G. (tr), 1998. Chicago - London: University of Chicago Press. (Original: Brisson, L. 1982. Platon, les mots et les myths. Paris: Maspero).

Chalmers, D. J. 2015. Why Isn't There More Philosophical Progress? Philosophy 9o(1), 3-31.

Collobert, C., Destrée, P. \& Gonzales, F. J. (eds.), 2012. Plato and Myth. Studies on the Use and Status of Platonic Myths (Mnemosyne Supplements 337). Leiden: Brill.

Corcilius, K. 2018. Aristotle and Thought Experiments. In: Stuart, M. T., Fehige, Y. \& Brown, R. J. (eds.), The Routledge Companion to Thought Experiments. London - New York: Routledge, 57-76.

Friedman, J. (2017). Inquiry and Belief Noûs 51(2), 296-315

Friedman, J. (2019). Why Suspend Judging? Noûs 53(2), 302-326.

Hintikka, J. \& Remes. U. 1974. The Method of Analysis. Its Geometrical Origin and Its General Significance. Dordrecht Boston: Reidel.

Ierodiakonou, K. 2005. Ancient Thought Experiments. A First Approach. Ancient Philosophy 25, 125-140.

Ierodiakonou, K. 2011. Remarks on the History of an Ancient Thought Experiment. In: Ierodiakonou, K. \& Roux, S. (eds.), Thought Experiments in Methodological and Historical Contexts. Leiden - Boston: Brill.

Ierodiakonou, K. 2018. The Triple Life of Thought Experiments. In: Stuart, M. T., Fehige, Y. \& Brown, R. J. (eds.), The Routledge Companion to Thought Experiments. London - New York: Routledge, 31-43.

Irwin, T. 1988. Aristotle's First Principles. Oxford: Clarendon Press.

Janka, M. \& Schäfer, C. (eds.), 2002. Platon als Mythologe: Neue Interpretationen zu den Mythen in Platons Dialogen. Darmstadt: Wissenschaftliche Buchgesellschaft.

Karamanolis, G. \& Politis, V. (eds.), 2018. The Aporetic Tradition in Ancient Philosophy. Cambridge: Cambridge University Press.

Menn, St. 2002. Plato and the Method of Analysis. Phronesis 47(3),193-223.

Partenie, C. 2018. Plato's Myths. In: Zalta, E.N. (ed.), The Stanford Encyclopedia of Philosophy (Fall Edition 2018), URL: <https://plato.stanford.edu/archives/fall2018/entries/plato-myths/>. Accessed:June 4, 2020.

Politis, V. 2003. Aristotle on Aporia and Searching in Metaphysics. Proceedings of the Boston Area Colloquium in Ancient Philosophy 18, 145-182.

Politis, V. 2004. Aristotle and the Metaphysics. London - New York: Routledge.

Politis, V. 2006. Aporia and Searching in the Early Plato. In Judson, L. \& Karasmanis, V. (eds.), Remembering Socrates: Philosophical Essays. Oxford: Oxford University Press, 88-109.

Politis, V. 2008. The Place of Aporia in Plato's Charmides. Phronesis 53, 1-34. 
Politis, V. 2012. What Do the Arguments in the Protagoras Amount To? Phronesis 57(3), 209-239.

Politis, V. 2015. The Structure of Enquiry in Plato's Early Dialogues. Cambridge: Cambridge University Press.

Politis, V. (forthcoming). Plato's Essentialism. Reinterpreting the Theory of Forms. Cambridge: Cambridge University Press.

Stuart, M. T., Fehige, Y. \& Brown, R. J. (eds.), The Routledge Companion to Thought Experiments. London - New York: Routledge.

Turri, J., Alfano, M. \& Greco, J. Virtue Epistemology. In: Zalta, E.N. (ed.), The Stanford Encyclopedia of Philosophy (Fall 2019 Edition), URL: <https://plato.stanford.edu/archives/fall2o19/entries/epistemology-virtue/>.

Wieland, W. 1962. Die aristotelische Physik. Göttingen: Vandenhoeck \& Ruprecht. 